\title{
Targeting the urokinase plasminogen activator receptor enhances gene transfer to human airway epithelia
}

\author{
Paola T. Drapkin, ${ }^{1,2}$ Catherine R. O'Riordan, ${ }^{6}$ Su Min Yi, ${ }^{5}$ John A. Chiorini, ${ }^{7}$ \\ Jonathan Cardella, ${ }^{8}$ Joseph Zabner, ${ }^{1,3}$ and Michael J. Welsh ${ }^{1,2,3,4}$ \\ ${ }^{1}$ Program in Gene Therapy, \\ ${ }^{2}$ Howard Hughes Medical Institute, \\ ${ }^{3}$ Department of Internal Medicine, \\ ${ }^{4}$ Department of Physiology and Biophysics, and \\ ${ }^{5}$ Department of Otolaryngology, University of Iowa College of Medicine, Iowa City, Iowa 52242, USA \\ ${ }^{6}$ Genzyme Corp., Framingham, Massachusetts 01701, USA \\ ${ }^{7}$ Gene Therapy and Therapeutics Branch, National Institute for Disease Control Research, National Institutes of Health, \\ Bethesda, Maryland 20892, USA \\ ${ }^{8}$ The Toronto Hospital, General Division, Thoracic Surgery Research Laboratory, Toronto, Ontario, Canada M5G 1L7
}

Address correspondence to: Michael J. Welsh, Howard Hughes Medical Institute, University of Iowa College of Medicine, 500 EMRB, Iowa City, Iowa 52242, USA. Phone: (319) 335-7619; Fax: (319) 335-7623; E-mail: mjwelsh@blue.weeg.uiowa.edu.

Received for publication November 5, 1999, and accepted in revised form January 24, 2000.

\begin{abstract}
Developing gene therapy for cystic fibrosis has been hindered by limited binding and endocytosis of vectors by human airway epithelia. Here we show that the apical membrane of airway epithelia express the urokinase plasminogen activator receptor ( $\mathrm{UPAR})$. Urokinase plasminogen activator (uPA), or a 7-residue peptide derived from this protein (u7-peptide), bound the receptor and stimulated apical endocytosis. Both ligands enhanced gene transfer by nonspecifically bound adenovirus and adenoassociated virus vectors and by a modified adenovirus vector that had been coupled to the u7-peptide. These data provide the first evidence that targeting an apical receptor can circumvent the two most important barriers to gene transfer in airway epithelia. Thus, the uPA/uPAR system may offer significant advantages for delivering genes and other pharmaceuticals to airway epithelia.
\end{abstract}

J. Clin. Invest. 105:589-596 (2000).

\section{Introduction}

Gene transfer of the cystic fibrosis transmembrane conductance regulator (CFTR) cDNA to airway epithelia could provide an important new treatment for cystic fibrosis (CF) lung disease (1). Despite the demonstrated ability of several vectors to express CFTR and correct the $\mathrm{Cl}^{-}$channel defect in human airway epithelia in vitro and in vivo (see refs. 2-6 for review), a severe inefficiency in delivering the CFTR transgene has prevented the development of gene transfer as a new treatment. The two most important factors for the inefficiency are limited binding of vector to the apical surface of differentiated human airway epithelia and limited endocytosis across the apical membrane. A paucity of apical receptors prevents binding of viral vectors, including adenovirus (7-9), adeno-associated virus (AAV) (10-12), and retroviral vectors (13), as well as nonviral vectors, including cationic lipids (14-16). Compounding the limited vector binding, and in contrast to observations in cell lines, the rate of endocytosis across the apical membrane of differentiated airway epithelia is low and may limit gene transfer for adenovirus, $\mathrm{AAV}$, and nonviral vectors $(8,16,17)$.

A method that increased vector binding and endocytosis might enhance both viral and nonviral vector gene transfer to airway epithelia. One strategy to circumvent the lack of apical receptors is to nonspecifically increase vector binding. For example, earlier work showed enhancement of gene transfer when adenovirus or AAV-vector binding was increased by incorporating virus in a calcium phosphate $(\mathrm{CaPi})$ coprecipitate (18-20). However, this delivery method did not increase endocytosis across the apical surface (21). An alternative strategy is to identify receptors that are normally expressed on the apical surface of human airway epithelia. Coupling or engineering the receptor ligand to the vector might then specifically target the vector to the receptor (22-27). An ideal ligand would not only enhance binding, but also stimulate endocytosis.

For a target we considered GPI-linked receptors because they reside on the apical surface of polarized epithelia (28). Although GPI-linked proteins do not have transmembrane or cytoplasmic domains, when the adenovirus receptor was targeted to the membrane by a GPI linkage, it bound adenovirus and enhanced gene transfer (29). Gross et al. (30) found that pulmonary alveolar epithelial cells express the urokinase plasminogen activator (uPA) and its receptor (uPAR), a GPI-linked receptor. Therefore, we hypothesized that uPAR might also be expressed in airway epithelia and that this ligand-receptor system might be used to enhance gene transfer. A $55-\mathrm{kD}$ secreted serine protease, uPA cleaves plasminogen to the active plasmin and can degrade components of the extracellular matrix $(31,32)$. The carboxy-terminal portion of uPA is catalytically active, whereas the amino-terminal portion 
of uPA binds with high affinity to uPAR (33). uPar is a 55-65-kD glycoprotein (34), involved in both clathrindependent and clathrin-independent endocytosis (35). In addition to binding uPA, uPAR serves as a cellular adhesion receptor for vitronectin and as a signaling receptor (36-38). uPAR also interacts with several cell surface proteins including integrins, low-density lipoprotein receptor-related peptide, very-low-density lipoprotein receptor, megalin and the mannose-6-phosphate/insulin-like growth factor-II receptor (39-41).

\section{Methods}

Cells, cultures, and explants. Human airway epithelia were obtained from tracheas and bronchi of lungs removed for organ donation. The University of Iowa In Vitro Models Core (Iowa City, Iowa, USA) isolated cells by enzyme digestion as described previously $(42,43)$. Freshly isolated cells were seeded at a density of $5 \times 10^{5}$ cells $/ \mathrm{cm}^{2}$ onto collagen-coated, $0.6-\mathrm{cm}^{2}$ diameter Millicell polycarbonate filters (Millipore Corp., Bedford, Massachusetts, USA). Cultures were maintained in a $37^{\circ} \mathrm{C}$ incubator with $7 \% \mathrm{CO}_{2}$ and air. After 24 hours, media from the mucosal side was removed, and cells were cultured at the air-liquid interface. Culture media consisted of a 1:1 mixture of DMEM and Ham's F12, supplemented with $2 \%$ Ultraser G (Biosepra SA, Cedex, France), 100 units/mL penicillin, $100 \mu \mathrm{g} / \mathrm{mL}$ streptomycin, $50 \mu \mathrm{g} / \mathrm{ml}$ gentamycin, and $2 \mu \mathrm{g} / \mathrm{ml}$ fluoconazole.

Freshly excised monkey trachea was maintained on ice. Explants $\left(1 \mathrm{~cm}^{2}\right)$ were maintained in 1:1 DMEM and Ham's F-12, supplemented with $2 \%$ Ultraser G (Biosepra SA) in a $37^{\circ} \mathrm{C}$ incubator.

Fluorescence-activated cell analysis. Human airway epithelia or COS-1 cells were washed once with PBS, with $0.9 \mathrm{mM} \mathrm{Ca}^{2+}$ and with $0.9 \mathrm{mM} \mathrm{Mg}^{2+}$. Epithelial cells were released from their substratum by a $10-$ minute incubation in $0.05 \%$ trypsin and $0.53 \mathrm{mM}$ EDTA at $37^{\circ} \mathrm{C}$. This treatment releases all the cells from the permeable support. The cell suspension was collected and $1 \mathrm{~mL}$ of Eagle's media was added. Cells were centrifuged at $64 \mathrm{~g}$ for 5 minutes. Cells were washed with PBS and centrifuged again. Cells were then treated with either PBS alone or with a murine, anti-human uPAR antibody (1:100; American Diagnostica, Greenwich, Connecticut, USA) at $4{ }^{\circ} \mathrm{C}$ for 2 hours. After incubation, cells were centrifuged at $64 \mathrm{~g}$ for 5 minutes. Cells were washed with PBS and then incubated with FITC-conjugated anti-mouse IgG (1:500; Jackson ImmunoResearch Laboratories, West Grove, Pennsylvania, USA) for 1 hour at room temperature. Cells were centrifuged for 5 minutes at $64 \mathrm{~g}$, resuspended in PBS, and analyzed by FACS.

Immunocytochemistry. Human airway epithelia were chilled on ice for 15 minutes. All incubations were performed at $4^{\circ} \mathrm{C}$ and followed by 3 washings of PBS. Cells were incubated with $0.05 \mathrm{M}$ glycine for 25 minutes to quench free aldehydes, then with 5\% BSA for 1 hour to block nonspecific binding. Anti-human uPAR antibody (1:100; American Diagnostica) in PBS was added to the apical surface and incubated for 3 hours. FITC-conjugated anti-mouse-IgG (1:500, Jackson ImmunoResearch) in PBS was added apically for 1 hour. Cells were fixed with 4\% paraformaldehyde for 15 minutes, mounted on glass slides, and studied using confocal microscopy (MRC1024; Bio-Rad Laboratories, Richmond, California, USA). In some cases, ethidium bromide was then applied to the permeabilized cells. Control cells were treated with FITCconjugated anti-mouse IgG only.

ELISA on human airway epithelia. Human airway epithelia were chilled on ice for 15 minutes. Following 3 washes with PBS, nonspecific binding was blocked with $1 \times$ TBS (137 mM NaCl, 2.7 mM KCl, $2.5 \mathrm{mM}$ Tris) and 5\% milk for 1 hour on ice. All incubations were followed by 3 washes with PBS, unless otherwise indicated. Varying concentrations of uPA were applied apically for $30 \mathrm{~min}-$ utes on ice. Cells were then fixed with $4 \%$ paraformaldehyde for 15 minutes. Bound uPA was detected by apical incubation with a mouse anti-human uPA mAb (1:1000 in $1 \times \mathrm{TBS}+5 \%$ milk; American Diagnostica) for 1 hour at $37^{\circ} \mathrm{C}$. Anti-mouse IgG-HRP (1:5000 in $1 \times \mathrm{TBS}+5 \%$ milk; Amersham Pharmacia Biotech, Inc., Piscataway, New Jersey, USA) was then applied apically for 1 hour at $37^{\circ} \mathrm{C}$. TMBD substrate buffer $\left(3,3^{\prime}, 5,5^{\prime}\right.$, tetramethyl benzidine dihydrochloride in $0.1 \mathrm{M}$ citric acid, $0.2 \mathrm{M}$ $\mathrm{Na}_{2} \mathrm{HPO}_{4}, \mathrm{pH}$ 5.0) was added apically for 5 minutes at room temperature in the dark. TMBD substrate buffer was removed, and the reaction was stopped with $2 \mathrm{~N}$ $\mathrm{H}_{2} \mathrm{SO}_{4}$. Color change of substrate was read at $450 \mathrm{~nm}$ $\left(\mathrm{OD}_{450}\right)$ in a plate reader.

Assay for fluid-phase endocytosis. Cells were chilled on ice for 15 minutes and then incubated with $50 \mathrm{nM}$ uPA or $0.15 \mu \mathrm{M} u 7$-peptide added to the apical surface for 30 minutes at $4^{\circ} \mathrm{C}$. After 3 washes in PBS, cells were incubated with $0.5 \mathrm{mg} / \mathrm{mL}$ Texas red-labeled fixable dextran (3,000 MW; Molecular Probes, Eugene, Oregon, USA) for 10 minutes at $37^{\circ} \mathrm{C}$. After 3 washes in PBS, cells were fixed with $4 \%$ paraformaldehyde, mounted onto glass slides with VectaShield (Vector Laboratories, Inc., Burlingame, California, USA), and viewed by fluorescence microscopy. Control cells were incubated with Texas red-labeled dextran alone to measure basal levels of endocytosis. Monkey tracheal explants were assayed as described for primary cell cultures. To evaluate timedependent changes, cells were treated as described above with uPA ( $50 \mathrm{nM})$ followed by incubations in Texas red dextran of $5,10,30$, or 60 minutes at $37^{\circ} \mathrm{C}$. To evaluate the requirement of a GPI-anchored receptor for uPAstimulated endocytosis, human airway epithelia were incubated with phosphatidylinositol-specific phospholipase C (PI-PLC from Bacillus cereus; Molecular Probes) for 2 hours at $37^{\circ} \mathrm{C}$ followed by 3 washes in PBS before incubations with uPA and Texas red dextran. This treatment with PI-PLC did not alter transepithelial resistance.

Western blot for UPAR. Human airway epithelia, MDAMB23 (a breast cancer cell line), and H441 cells (an adenocarcinoma lung cancer cell line) were solubilized with $0.1 \%$ Triton X-100 (Pierce Chemical Co., Rockford, Illinois, USA). Cells were spun down, and the soluble 


\section{Figure 1}

Expression of UPAR in differentiated human airway epithelia. FACS analysis of uPAR staining in COS-1 cells (a) and differentiated human airway epithelia (b). (c) Projection of 180- $\mu \mathrm{m}$ thick X-Z series of confocal images. Green is staining from anti-uPAR antibody and red is ethidium bromide fluorescence to identify cells. (d) Western blot for UPAR. Lane A is from MDAMB231 cells, lane B is from $\mathrm{H} 441$ cells, and lane $C$ is from human airway epithelia. uPAR migrates at $\sim 55 \mathrm{kDa}$. a

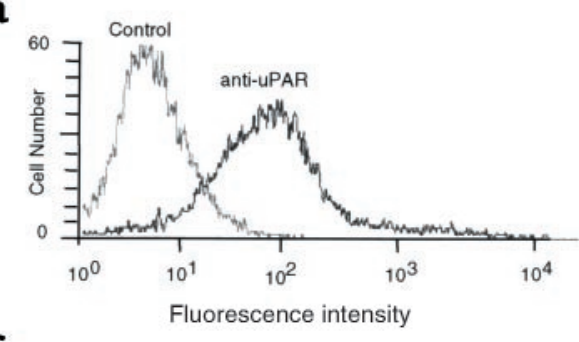

c

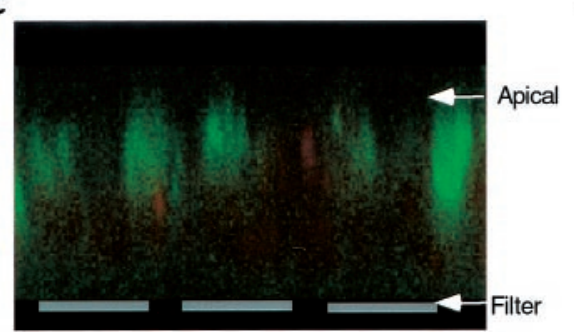

b

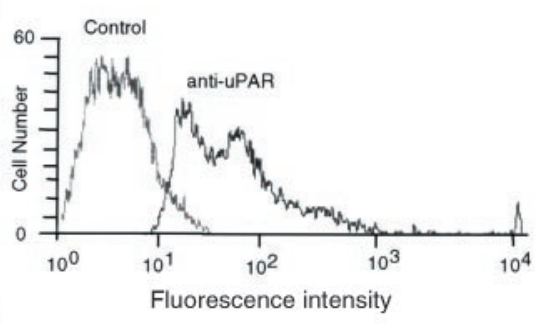

d

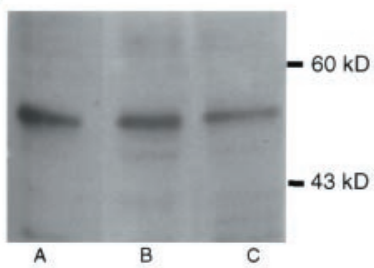

phase was run on a $10 \%$ acrylamide gel under reducing conditions. Proteins were transferred to a PVDF transfer membrane (Millipore Corporation) and then blocked with 5\% BSA for 1 hour. After extensive washes in TTBS $(137 \mathrm{mM} \mathrm{NaCl}, 2.7 \mathrm{mM} \mathrm{KCl}, 2.5 \mathrm{mM}$ Tris, $0.05 \%$ Tween20), mouse anti-human uPAR antibody (1:1000; American Diagnostica) was applied for 2 hours. After washes, anti-mouse-IgG-HRP (1:10,000; American Pharmacia Biotech) was applied for 1 hour. The blot was developed using Super Signal (Pierce Chemical Co.) for 1 minute and exposed to film (Kodak X-O-Mat; Sigma Chemical Co., St. Louis, Missouri, USA).

Recombinant adenovirus and reagents. Recombinant adenovirus vectors expressing $\beta$-galactosidase (Ad $2 / \beta$-Gal4) and CFTR (Ad2/CFTR-16) were prepared as described previously (19) by the University of Iowa Gene Transfer Vector Core at titers of approximately $10^{10}$ infectious units (IU)/mL. Recombinant AAV2 vector expressing $\beta$-galactosidase was prepared at approximately $1 \times 10^{7} \mathrm{IU} / \mathrm{mL}$, as previously described (44). Pseudotransduction cannot explain the results of transgene expression because we detected no $\beta$-galactosidase activity 1 hour after vector administration; with AAV the transgene was expressed 2 weeks after vector application, and the generation of regulated transepithelial $\mathrm{Cl}^{-}$transport could not be explained in this way.

The uPA was purchased from either CalbiochemNovabiochem Corp (source: human urine; San Diego, California, USA) or Sigma-Aldrich Inc. (source: human kidney cells, Milwaukee, Wisconsin, USA). The u7-peptide (CLNGGTC), a scrambled peptide (GTCGNCL), and a mutated peptide (CLNFFTC) were synthesized by the University of Iowa Peptide Synthesis Core.

Covalent attachment of u7-peptide to adenovirus. Bifunctional polyethylene glycol (PEG) molecules were added to virus at room temperature for 60 minutes to allow coupling of PEG to viral surface proteins (45). Unreacted PEG was separated from the PEG-modified virus by $\mathrm{CsCl}$ centrifugation as described previously, and PEG-modified virus (Ad2/PEG) was finally dialyzed into PBS ( $\mathrm{pH} 7$ ) containing $5 \%$ sucrose. The u7-peptide and mutated peptide synthesized to include a terminal cysteine with a free sulfhydryl were dissolved in PBS containing 5\% sucrose to a final concentration of $10 \mathrm{mM}$ and were added to 1.5 $\times 10^{12}$ particles of Ad2/PEG at a final concentration of 1 $\mathrm{mM}$. The peptide and PEG virus were allowed to couple for 4 hours at room temperature. Unreacted peptide was removed from Ad2/PEG/peptide by dialysis into PBS containing $5 \%$ sucrose.

Evaluation of gene transfer. The apical surface of human airway epithelia was washed once with PBS. Adenovirus was applied at a moi of 50 to the apical surface for 30 minutes at $37^{\circ} \mathrm{C}$. Adenovirus was applied either alone or in a CaPi coprecipitate formed as described previously $(18,19)$. After 3 washes, cells were returned to the incubator and assayed for gene transfer 48 hours later. AAV2 was applied at a moi of less than 1 to the apical surface for 30 minutes at $37^{\circ} \mathrm{C}$. AAV2 was applied either alone or on a CaPi coprecipitate formed as described previously for adenovirus $(18,19)$. After 3 washes, cells were returned to the incubator and assayed for gene transfer 14 days later. Total $\beta$-galactosidase activity (in relative light units [RLU]) was measured using a commercially available technique (Galacto-Light; Tropix, Bedford,

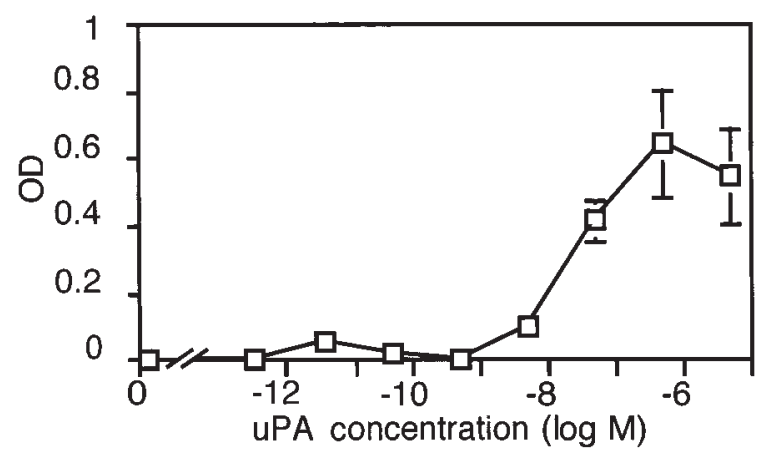

Figure 2

Concentration-dependent binding of uPA to differentiated human airway epithelia. Data are OD at $450 \mathrm{nM}$, indicating color change in $\operatorname{ELISA}$ assay $(n=5)$. 


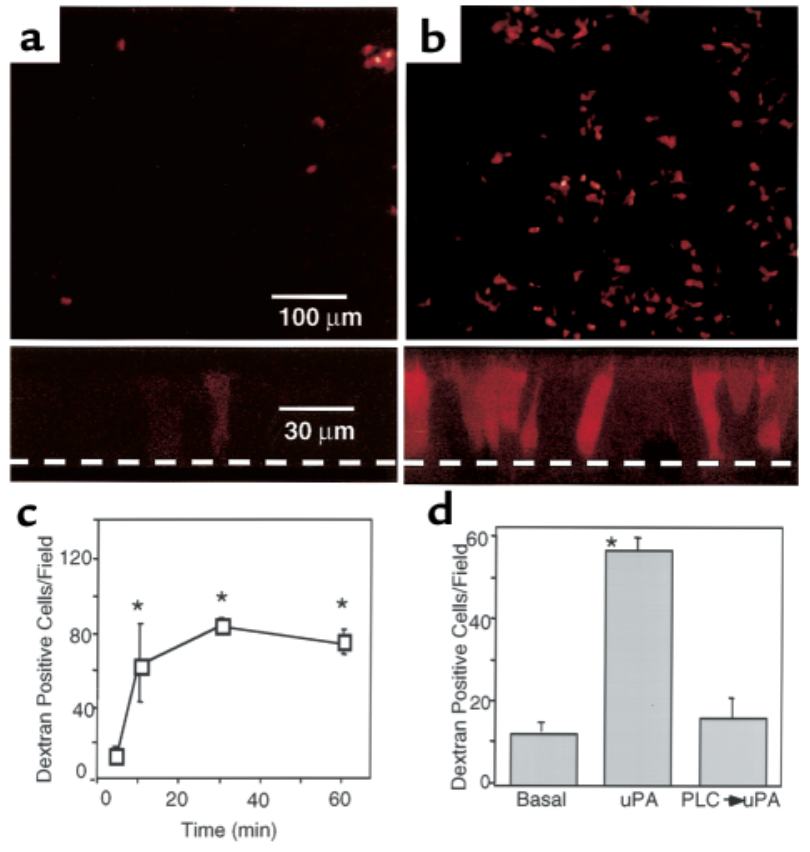

Figure 3

Stimulation by uPA of fluid-phase endocytosis by differentiated human airway epithelia measured as uptake of Texas red-labeled dextran. (a, b) En face images (top) and confocal X-Z series (bottom) of labeled dextran uptake under basal (a) conditions and after application of $50 \mathrm{nM}$ uPA (b). Dashed line indicates filter. (c) Time course of dextran uptake after application of uPA ( $50 \mathrm{nM})(\mathbf{d})$. Graph shows the effect of PI-PLC on uPA-mediated stimulation of dextran uptake. $n=10,{ }^{*} P<0.05$.

Massachusetts, USA). Background activity in the absence of vector was subtracted. $\beta$-galactosidase activity was normalized to total milligrams of protein.

Monkey tracheal explants were infected as described for primary cells. Following infection, explants were maintained in a $37^{\circ} \mathrm{C}$ incubator for 72 hours and then stained with X-gal. For X-gal staining, explants were fixed with $1.8 \%$ formaldehyde and $2 \%$ glutaraldehyde, and then incubated at $37^{\circ} \mathrm{C}$ in X-gal solution overnight.

Measurement of transepithelial electrical properties. Epithelia were mounted in modified Ussing chambers (Jim's Instruments, Iowa City, Iowa, USA) and bathed with Ringer's solution on their submucosal side $(135 \mathrm{mM} \mathrm{NaCl}, 2.4$ $\mathrm{mM} \mathrm{K}_{2} \mathrm{HPO}_{4}, 0.6 \mathrm{mM} \mathrm{KH}_{2} \mathrm{PO}_{2}, 1.2 \mathrm{mM} \mathrm{CaCl}_{2}, 1.2 \mathrm{mM}$ $\mathrm{MgCl}_{2}$, and $5 \mathrm{mM}$ HEPES, $\mathrm{pH} 7.4$, and $10 \mathrm{mM}$ dextrose). The mucosal surface was bathed in the identical solution, except that $135 \mathrm{mM}$ sodium gluconate replaced the 135 $\mathrm{mM} \mathrm{NaCl}$. In this way a transepithelial $\mathrm{Cl}^{-}$-concentration gradient was established to magnify changes in $\mathrm{Cl}^{-}$transport. Transepithelial $\mathrm{Na}^{+}$transport was blocked with mucosal amiloride $(10 \mu \mathrm{M})$. Mucosal diisothiocyanatostilbene-2,2'-disulfonate (DIDS; $100 \mu \mathrm{M}$ ) blocked nonCFTR $\mathrm{Cl}^{-}$transport. The cAMP agonists, forskolin (10 $\mu \mathrm{M})$ and IBMX $(100 \mu \mathrm{M})$, were applied to both solutions to stimulate transepithelial $\mathrm{Cl}^{-}$transport via CFTR.

\section{Results}

Human airway epithelia express UPAR at the apical surface. To learn whether human airway epithelia express
uPAR, we studied primary cultures of epithelia grown at the air-liquid interface under conditions that allow them to differentiate and develop morphologic and functional properties of the native epithelium $(42,43)$. After at least 2 weeks in culture, cells were dissociated from the permeable support, probed with an antihuman uPAR $\mathrm{mAb}$, and labeling was detected by fluorescence-activated cell sorting. Figure 1a shows results from COS- 1 cells, which are known to express uPAR (46); Figure $1 \mathrm{~b}$ shows that human airway epithelia also express UPAR. Figure $1 \mathrm{~d}$ shows that airway epithelia contain uPAR transcripts. Immunocytochemistry of unpermeabilized epithelia detected uPAR (green fluorescence) on the apical surface (Figure 1c). These data indicate that uPAR is present on the apical surface, suggesting that it might serve as a target for ligand applied to the lumenal surface.

In airway epithelia uPA binds uPAR with high affinity. We tested binding of uPA to differentiated human airway epithelia, using a modified ELISA. Figure 2 shows that uPA bound to the apical surface; half-maximal binding occurred at approximately $50 \mathrm{nM}$. Studies in HeLa cells reported an EC50 for binding of UPA to UPAR of approximately $400 \mathrm{nM}$ (47). Binding of uPA was specific because u7-peptide $(0.15 \mu \mathrm{M})$ successfully com-
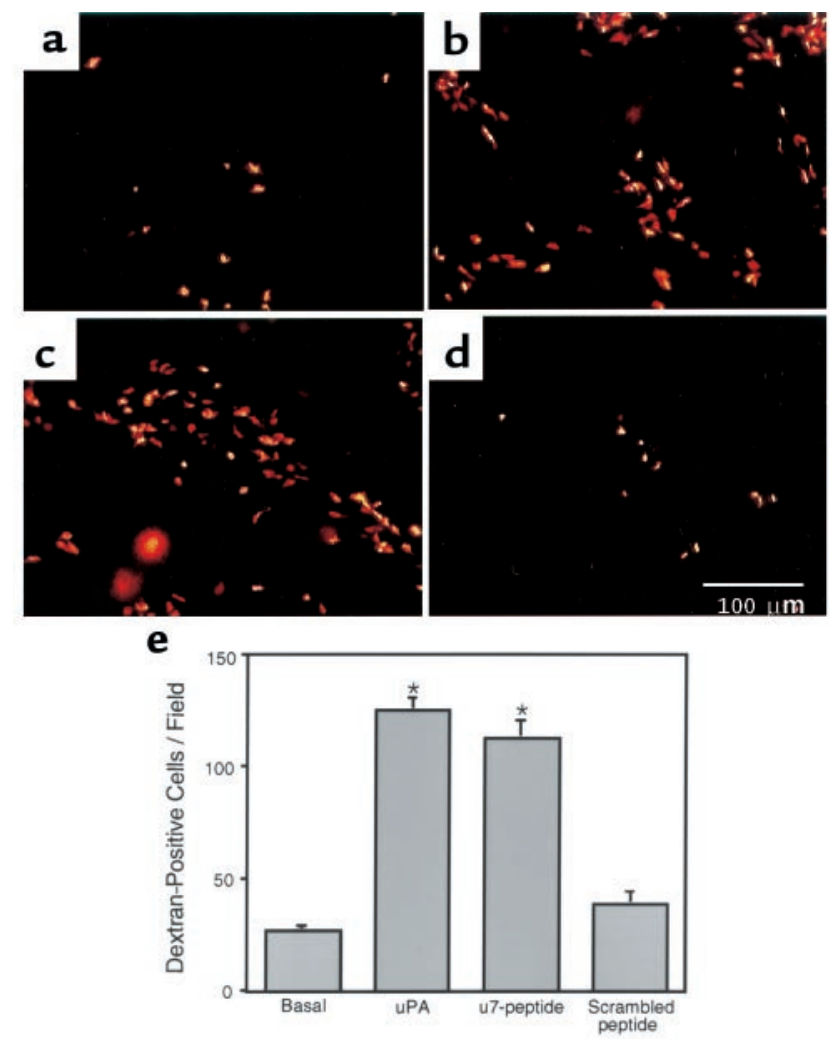

Figure 4

Apical fluid-phase endocytosis by human airway epithelia stimulated by uPA and u7-peptide. Data are en face images showing Texas red-labeled dextran uptake. Shown are basal endocytosis (a), endocytosis after apical application of $50 \mathrm{nM}$ uPA (b), $0.15 \mu \mathrm{M}$ u7-peptide (c), or $0.15 \mu \mathrm{M}$ scrambled u7-peptide (d), effect of uPA and peptides on number of cells showing endocytosis (e). $n=5,{ }^{*} P<0.05$. 
pleted binding whereas the mutated peptide $(0.15 \mu \mathrm{M})$ did not (data not shown). These data suggest that a high-affinity interaction between UPA and uPAR is preserved in human airway epithelia.

Apical uPA increases fluid-phase endocytosis. To learn whether uPA binding could stimulate endocytosis, we measured uptake of Texas red-conjugated dextran, a fluid-phase marker. Figure 3 a shows that under basal conditions, few cells took up dextran from the apical solution. This result is consistent with earlier work suggesting a low level of apical endocytosis $(8,16)$. However, after apical addition of uPA $(50 \mathrm{nM})$, there was a marked increase in the number of cells that took up the fluid-phase marker (Figure 3b). We determined the total number of cells in a microscopic field by staining all nuclei with 4'6-diamidine-2'-phenylindole dihydrochloride (DAPI). Under basal conditions, $0.9 \pm 0.2 \%$ of cells were dextran-positive, and with uPA $4.0 \pm 0.5 \%$ of cells were positive. Because the epithelium is pseudostratified and not all cells touch the apical surface, these numbers underestimate the percentage of cells that have access to the apical surface and that will be involved in transepithelial transport. Vertical sections through the cells show little dextran uptake under basal conditions and increased labeling of the cell following apical uPA (lower portion of Figure 3, a and b). These data suggest that ligand binding to UPAR stimulates endocytosis. However, they also suggest that stimulation of endocytosis is heterogeneous, with not all cells participating. Perhaps this is because not all the cells express receptor, as suggested by Figure 1c, or because the amount of receptor varies on individual cells.

To determine how quickly internalization follows ligand binding, we incubated epithelia with apical uPA $(50 \mathrm{nM})$ at $4^{\circ} \mathrm{C}$ for 30 minutes. Cells were then incubated with labeled dextran for $5-60$ minutes at $37^{\circ} \mathrm{C}$. An increase in stimulated uptake was apparent by 5 minutes, and uptake continued to increase for at least 30 minutes (Figure 3c). By 60 minutes, the dextran fluorescence developed a more vesicular appearance, suggesting intracellular accumulation in late-stage endosomes or lysosomes (not shown). Removal of uPAR by incubation with PI-PLC, which cleaves GPI linkages, eliminated the endocytosis response (Figure 3d). These data indicate that ligand binding to uPAR rapidly and potently stimulates endocytosis.

The u7-peptide stimulates fluid-phase endocytosis. The ability to use a small uPA-derived peptide instead of uPA itself would simplify the incorporation or engineering of the ligand into gene transfer vectors. Use of a peptide would also eliminate potential unwanted effects from delivering the enzymatic portion of the fulllength uPA molecule. Studies by Appella et al. (33), identified an $\mathrm{NH}_{2}$-terminal portion of uPA that is key for binding to uPAR. They showed that residues 13-19 (CLNGGTC) are a region of high-sequence conservation involved in binding. We synthesized this peptide (u7-peptide) and examined its ability to stimulate endocytosis. As with full-length uPA, application of u7-peptide to the apical surface of human airway epithelia stimulated fluid-phase endocytosis, whereas an equivalent peptide in which the sequence was scrambled (scrambled peptide) did not (Figure 4). Of the total number of DAPI-stained cells, $3.6 \pm 0.7 \%$ were positive for endocytosis with u7-peptide and $1.2 \pm 0.5 \%$ were positive with the scrambled peptide. These data show that binding of a small peptide from uPA stimulates endocytosis. Because the u7-peptide does not contain the sequences (i.e., the proteinase domain) required for uPA to bind PAI-1 $(36,48,49)$, these data also indicate that a uPA/PAI-1 complex is not required to stimulate endocytosis in human airway epithelia.

Gene transfer by nonspecifically bound vector to human airway epithelia is enhanced by $u P A$. We tested the ability of uPA to enhance gene transfer by nonspecifically bound vector. In earlier work we showed that incorporating recombi-

a

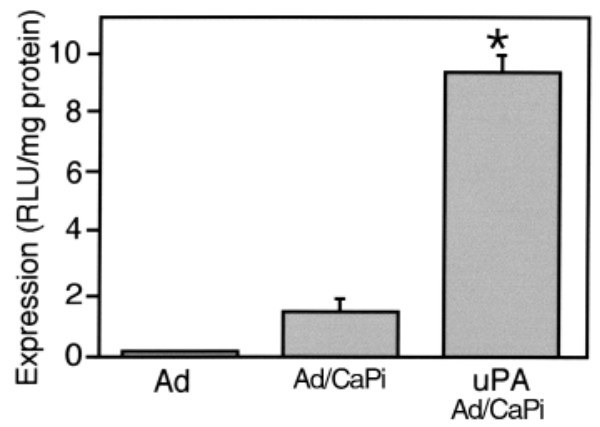

b

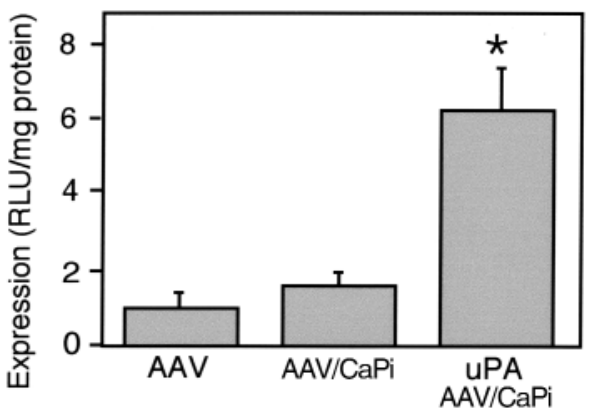

c

\section{Figure 5}

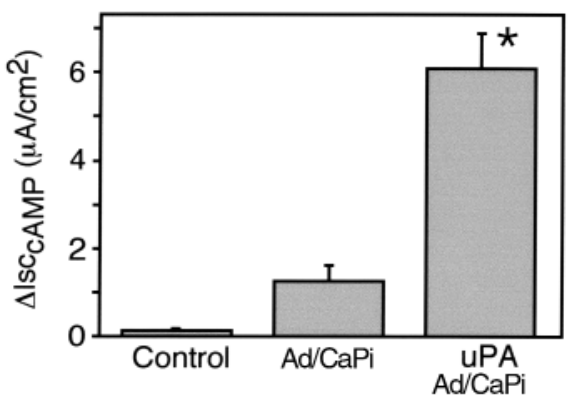

uPA stimulation of gene transfer to normal and CF airway epithelia. (a) Apical application of uPA (50 nM) before infection with Ad2/ $\beta$ Gal-4 in a CaPi coprecipitate $(n=4)$. (b) Apical application of uPA ( $50 \mathrm{nM})$ before infection with recombinant AAV in a CaPi coprecipitate $(n=10)$. (c) cAMP-stimulated increase in short-circuit current $(\Delta \mathrm{Isc})$ in CF airway epithelia treated with Ad2/CFTR-16 delivered in a CaPi coprecipitate $(n=4) .{ }^{*} P<0.05$. 
nant adenovirus or AAV in CaPi coprecipitates increases nonspecific virus binding to the apical surface and thereby enhances gene transfer (18-20). However, administration of CaPi coprecipitates does not increase the rate of apical endocytosis, and thus uptake depends on the basal rate of endocytosis (21). Thus, we reasoned that treatment of airway epithelia with a virus/CaPi complex to increase vector binding, plus uPA to increase apical endocytosis, would enhance gene transfer. To test this hypothesis, uPA $(50 \mathrm{nM})$ was applied to the apical surface of human airway epithelia. Then adenovirus/CaPi coprecipitates were added, and cells were assayed for gene transfer 48 hours later. Treatment with uPA increased gene transfer 8- to 10-fold compared with delivery of an adenovirus/CaPi coprecipitate alone (Figure 5a). We obtained similar results with an AAV vector; Figure $5 \mathrm{~b}$ shows that UPA enhanced gene transfer measured 2 weeks after AAV was delivered in a CaPi coprecipitate.

Earlier work showed that disrupting epithelial tight junctions allowed access of viral vectors to the basolateral surface where they could bind receptors $(9,12,13)$. We found no effect of uPA or the u7-peptide on epithelial tight junction integrity as measured by transepithelial electrical resistance (data not shown). Moreover, the u7-peptide, which has no enzymatic activity, had an effect similar to uPA and stimulated fluid-phase endocytosis across the apical membrane. Finally, disrupting tight junctions by chelating $\mathrm{Ca}^{2+}$ did not enhance gene transfer by Ad/CaPi (R.W. Walters and M.J. Welsh, unpublished data). These data indicate that disruption of tight junctions did not account for the enhanced gene transfer.

We also tested the ability of uPA to enhance gene transfer and expression of CFTR in differentiated CF airway epithelia. Figure $5 c$ shows that gene transfer with an adenovirus expressing CFTR in a CaPi coprecipitate generated a cAMP-stimulated current. uPA further enhanced the correction. This result indicates that uPA targets cells involved in generating transepithelial $\mathrm{Cl}^{-}$transport.

Gene transfer to monkey airway epithelial explants is enhanced by UPA. As an additional test of UPA-mediated endocytosis and gene transfer, we studied freshly excised monkey tracheal explants. Figure 6a shows a control explant treated with FITC-dextran only; because with human epithelia there was a low level of basal endocytosis. In contrast, apical application of uPA stimulated endocytosis 3-fold over control levels (Figure 6, a-c). We also assayed the effect of uPA on Ad/CaPi-mediated gene transfer to explants. Control explants infected apically with Ad/CaPi alone had low levels of gene transfer (Figure 6d). However, if uPA was first applied apically and followed by $\mathrm{Ad} / \mathrm{CaPi}$, there was an approximately 8-fold increase in gene transfer (Figure 6, e and f). Thin sections of X-gal-stained explants showed both ciliated and nonciliated cells expressing transgene (Figure 6g). Based on
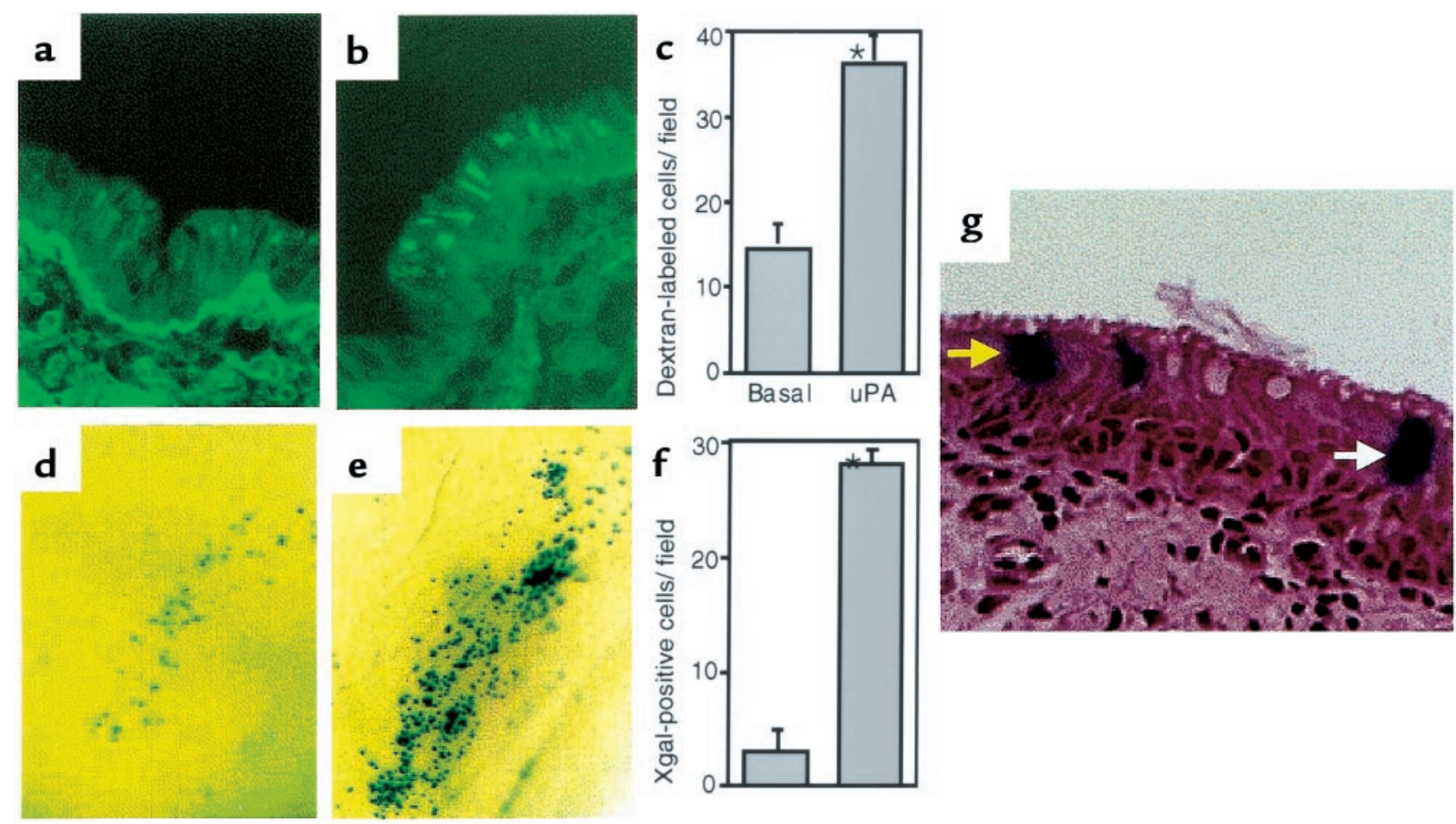

Figure 6

Endocytosis and gene transfer to freshly excised monkey tracheal explants. Fluid phase endocytosis measured as uptake of FITC-dextran under basal conditions (a), or after addition of $50 \mathrm{nM} \mathrm{uPA} \mathrm{(b);} \mathrm{trachea} \mathrm{shows} \mathrm{significant} \mathrm{background} \mathrm{fluorescence.} \mathrm{(c)} \mathrm{Quantitation} \mathrm{of}$ endocytosis $(n=12)$. X-gal-stained explants infected with Ad/CaPi coprecipitates alone (d) or following treatment with $50 \mathrm{nM}$ uPA (e). (f) Quantitation of gene transfer $(n=4)$. (g) Thin section of X-gal-stained uPA-treated explant; same explant as shown in $\mathbf{d}$. ${ }^{*} P<0.05$. White arrow indicates ciliated cells and yellow arrow indicates nonciliated cell. 
the number of DAPI-stained nuclei in a microscopic field, approximately $2 \%$ of the total number of cells were $\mathrm{X}$-gal positive. As described above, this percentage is an underestimate of the percentage of transduced cells that touch the apical surface.

Coupling a uPA-derived peptide to an adenovirus vector enhances gene transfer. Specific binding of vector to the apical surface would be preferable to nonspecific binding. Therefore, we tested the hypothesis that specifically targeting the uPAR could enhance gene transfer. Earlier work showed that PEG can be coupled to adenovirus vectors (45). Therefore, we linked the u7-peptide to PEG, which was coupled to the capsid of recombinant adenovirus expressing $\beta$-galactosidase. As controls, we coupled adenovirus to PEG alone or to PEG linked to a mutated peptide. Figure 7 shows that coupling the u7peptide to the PEG-modified vector enhanced gene transfer to airway epithelia 10 -fold.

\section{Discussion}

Binding to the cell surface and uptake across the apical membrane are two of the major barriers that limit viralmediated gene transfer to human airway epithelia (6-10, $12,13,17,43,50,51)$; once viral vectors have entered the cell, viral proteins accomplish subsequent steps in gene transfer. Nonviral vectors in which plasmid DNA encodes a transgene may also be limited by binding and by uptake (14-16); however, subsequent steps in the process of gene transfer such as escape from endosomes and entry of DNA into the nucleus also contribute to their inefficiency (14). Our data suggest that use of the uPA ligand and its receptor, uPAR, may provide a useful strategy to circumvent both the limited binding and low rate of endocytosis. The results support this strategy by using 2 different models of airway epithelia, differentiated human airway epithelia and freshly excised monkey trachea, and 2 different vectors, adenovirus and AAV.

The presence of uPAR on the apical membrane and the ability of both the uPA and u7-peptide ligands to stimulate apical endocytosis suggest the utility of the system. The ligand could be delivered as a separate component to enhance endocytosis of a vector that was nonspecifically bound to the apical surface, i.e., virus/CaPi coprecipitates. Our finding that gene transfer was enhanced by coating virus with $\mathrm{u} 7$-peptide/PEG provides more direct evidence that apical uPAR can be targeted to enhance gene transfer. However, it would be more desirable in future studies to engineer the peptide directly into the surface of any one of several vectors. The high affinity of uPA binding, with a half-maximal binding in the range of $50 \mathrm{nM}$, makes the receptor an attractive target.

Our data leave open the question of how uPA stimulates apical fluid-phase endocytosis. Binding of uPA might stimulate endocytosis of UPAR, thereby increasing fluid-phase endocytosis. Alternatively, uPA binding to uPAR might stimulate fluid-phase endocytosis, perhaps through a second messenger system. Because the GPI-linked uPAR lacks a transmembrane domain, stimulation of endocytosis through either mechanism

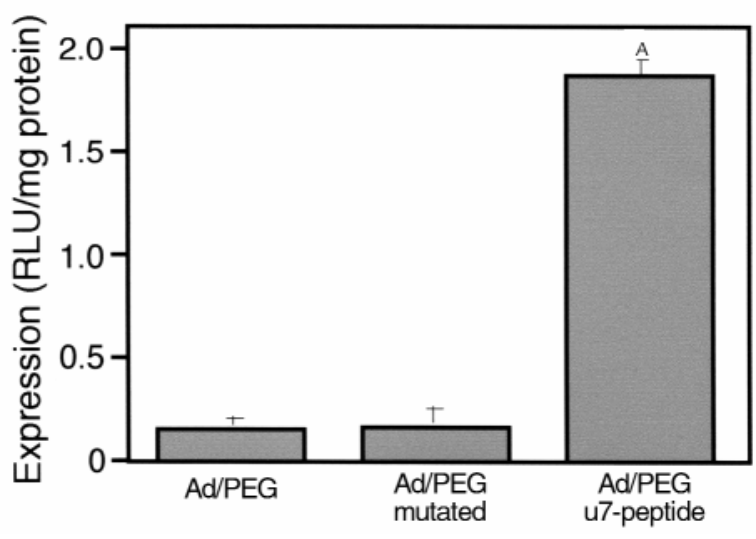

Figure 7

Targeting an adenovirus vector (Ad2/ $/ \mathrm{Gal}-4$ ) to uPAR by covalent association of $u 7$-peptide and PEG to the adenovirus capsid. Ad/PEG/mutated refers to a mutated u7-peptide sequence $(n=6)$. ${ }^{*} P<0.05$.

would require association with another transmembrane protein, several of which have been identified (34, 39-41). Because we obtained similar results with an $\mathrm{NH}_{2}$-terminal peptide from uPA that would not associate with PAI-1, our data suggest that binding of these 2 proteins is not responsible for endocytosis. Additional studies will be required to identify the molecular mechanisms that stimulate endocytosis.

The uPA/uPAR system may offer several advantages for future development of gene transfer. We used recombinant adenovirus and AAV to test the feasibility of enhancing gene transfer; thus, uPA might be used to target and facilitate gene transfer by several encapsidated vectors and, perhaps, nonviral and enveloped viral vectors. Future applications should explore the engineering of uPA peptides into viral surface proteins. For example, several peptides have been engineered into the adenovirus fiber protein and penton base and AAV capsid to target these viruses $(22-27,52)$. The uPA system might also be used to target other pharmaceuticals to airway epithelia. For example, lumenal delivery of a protein that contains part of uPA for targeting and uptake, fused to another peptide such as a single chain antibody, might have utility in airway disease. Finally, the high level of uPAR expression on several cancer cells (53-55) suggests this delivery system might have applications in cancer.

\section{Acknowledgments}

We thank Pary Weber, Phil Karp, Janice Launspach, Mike Seiler, Daniel Vermeer, and Theresa Mayhew for excellent assistance. We thank Francis Miller and Don Piegors for access to monkey trachea. We thank Sam Wadsworth for the gift of Ad2/CFTR-16. This work was supported by the National Heart, Lung and Blood Institute (NHLBI) and the Cystic Fibrosis Foundation (CFF). We appreciate help from the following cores: the University of Iowa In Vitro Cell Models Core (supported by the NHLBI, the CFF, and the National Institutes of Diabetes and Digestive and Kidney Diseases [NIDDK]); Universi- 
ty of Iowa Gene Transfer Vector Core (supported by the Roy J. Carver Charitable Trust, the NHLBI, the CFF, and the NIDDK); the Gene Transfer Morphology Core (supported by the NIDDK); and the University of Iowa Peptide Synthesis Core. M.J. Welsh is an Investigator of the Howard Hughes Medical Institute.

1. Welsh, M.J., Tsui, L.-C., Boat, T.F., and Beaudet, A.L. 1995. Cystic fibrosis. In The metabolic and molecular basis of inherited disease. C.R. Scriver, A.L. Beaudet, W.S. Sly, and D. Valle, editors. McGraw-Hill Inc. New York, NY. 3799-3876.

2. O'Neal, W.K., and Beaudet, A.L. 1994. Somatic gene therapy for cystic fibrosis. Hum. Mol. Genet. 3:1497-1502.

3. Crystal, R.G. 1995. Transfer of genes to humans: early lessons and obstacles to success. Science. 270:404-410.

4. Wilson, J.M. 1996. Adenovirus as gene-delivery vehicles. N. Engl. J. Med. 334:1185-1187.

5. Middleton, P.G., and Alton, E.W. 1998. Gene therapy for cystic fibrosis: which postman, which box? Thorax. 53:197-199.

6. Welsh, M.J. 1999. Gene transfer for cystic fibrosis. J. Clin. Invest. 104:1165-1166

7. Bergelson, J.M., et al. 1997. Isolation of a common receptor for Coxsackie B viruses and adenoviruses 2 and 5. Science. 275:1320-1323.

8. Pickles, R.J., et al. 1998. Limited entry of adenovirus vectors into well-differentiated airway epithelium is responsible for inefficient gene transfer.J. Virol. 72:6014-6023.

9. Walters, R.W., et al. 1999. Basolateral localization of fiber receptors limits adenovirus infection from the apical surface of airway epithelia. J. Biol. Chem. 274:10219-10226.

10. Teramoto, S., Bartlett, J.S., McCarty, D.X.X., Samulski, R.J., and Boucher, R.C. 1998. Factors influencing adeno-associated virus-mediated gene transfer to human cystic fibrosis airway epithelial cells: comparison with adenovirus vectors. J. Virol. 72:8904-8912.

11. Summerford, C., and Samulski, R.J. 1998. Membrane-associated heparin sulfate proteoglycan is a receptor for adeno-associated virus type 2 virions. J. Virol. 72:1438-1445.

12. Duan, D., Yue, Y., Yan, Z., McCray, P.B., Jr., and Engelhardt, J.F. 1998. Polarity influences the efficiency of recombinant adeno-associated virus infection in differentiated airway epithelia. Hum. Gene Ther 9:2761-2776.

13. Wang, G., et al. 1998. Influence of cell polarity on retrovirus-mediated gene transfer to differentiated human airway epithelia. J. Virol. 72:9818-9826.

14. Zabner, J., Fasbender, A.J., Moninger, T., Poellinger, K.A., and Welsh, M.J. 1995. Cellular and molecular barriers to gene transfer by a cationic lipid. J. Biol. Chem. 270:18997-19007.

15. Matsui, H., Johnson, L.G., Randell, S.H., and Boucher, R.C. 1997. Loss of binding and entry of liposome-DNA complexes decreases transfection efficiency in differentiated airway epithelial cells. J. Biol. Chem. 272:1117-1126.

16. Fasbender, A., Zabner,J., Zeiher, B.G., and Welsh, M.J. 1997. A low rate of cell proliferation and reduced DNA uptake limit cationic lipid-mediated gene transfer to primary cultures of ciliated airway epithelia. Gene Ther 4:1173-1180.

17. Goldman, M.J., and Wilson, J.M. 1995. Expression of alpha v beta 5 integrin is necessary for efficient adenovirus-mediated gene transfer in the human airway. J. Virol. 69:5951-5958.

18. Fasbender, A., et al. 1998. Incorporation of adenovirus in calcium phosphate precipitates enhances gene transfer to airway epithelia in vitro and in vivo. J. Clin. Invest. 102:184-193.

19. Lee, J.H., Zabner, J., and Welsh, M.J. 1999. Delivery of an adenovirus vector in a calcium phosphate coprecipitate enhances the therapeutic index of gene transfer to airway epithelia. Hum. Gene Ther. 10:603-613.

20. Walters, R.W., Duan, D., Engelhardt, J.F., and Welsh, M.J. 2000. Incorporation of AAV in a calcium phosphate coprecipitate improves gene transfer to airway epithelia in vitro and in vivo. J. Virol. 74:535-540.

21. Walters, R.W., and Welsh, M.J. 1999. Mechanism by which calcium phosphate coprecipitation enhances adenovirus mediated gene transfer. Gene Ther. 6:1845-1850.

22. Wickham, T.J., Carrion, M.E., and Kovesdi, I. 1996. Targeting of adenovirus penton base to new receptors through replacement of its RGD motif with other receptor-specific peptide motifs. Gene Ther. 2:750-756.

23. Wickham, T.J., et al. 1997. Increased in vitro and in vivo gene transfer by adenovirus vectors containing chimeric fiber proteins. J. Virol. 71:8221-8229.

24. Krasnykh, V., et al. 1998. Characterization of an adenovirus vector containing a heterologous peptide epitope in the HI loop of the fiber knob.J. Virol. 72:8144-1852.

25. Dmitriev, I., et al. 1998. An adenovirus vector with genetically modified fibers demonstrates expanded tropism via utilization of a coxsackievirus and adenovirus receptor-independent cell entry mechanism. J. Virol. 72:9706-9713.

26. Vigne, E., et al. 1999. RGD inclusion in the hexon monomer provides adenovirus type 5-based vectors with a fiber knob-independent pathway for infection. J. Virol. 73:5156-5161.

27. Girod, A., et al. 1999. Genetic capsid modifications allow efficient retargeting of adeno-associated virus type 2. Nat. Med. 5:1052-1056.
28. Lisanti, M.P., and Rodriguez-Boulan, E. 1991. Polarized sorting of GPIlinked proteins in epithelia and membrane microdomains. Cell Biol. Int. Rep. 15:1023-1049.

29. Wang, X., and Bergelson, J.M. 1999. Coxsackievirus and adenovirus receptor cytoplasmic and transmembrane domains are not essential for coxsackevirus and adenovirus infection. J. Virol. 73:2559-2562.

30. Gross, T.J., Simon, R.H., and Sitrin, R.G. 1990. Expression of urokinase type plasminogen activator by rat pulmonary alveolar epithelial cells. Am. J. Respir. Cell Mol. Biol. 3:449-456.

31. Fazioli, F., and Blasi, F. 1994. Urokinase-type plasminogen activator and its receptor: new targets for anti-metastatic therapy? Trends Pharmacol. Sci. 15:25-29.

32. Chapman, H.A. 1997. Plasminogen activators, integrins, and the coordinated regulation of cell adhesion and migration. Curr. Opin. Cell Biol. 9:714-724.

33. Appella, E., et al. 1987. The receptor-binding sequence of urokinase. A biological function for the growth-factor module of proteases. J. Biol. Chem. 262:4437-4440

34. Blasi, F., et al. 1994. The urokinase receptor: structure, regulation and inhibitor-mediated internalization. Fibrinolysis. 8:182-188.

35. Vilhardt, F., Nielsen, M., Sandvig, K., and van Deurs, B. 1999. Urokinase-type plasminogen activator receptor is internalized by different mechanisms in polarized and nonpolarized Madin-Darby canine kidney epithelial cells. Mol. Biol. Cell. 10:179-195.

36. Wei, Y., et al. 1994. Identification of the urokinase receptor as an adhesion receptor for vitronectin. J. Biol. Chem. 269:32380-32388.

37. Robinson, P.J. 1997. Signal transduction via GPI-anchored membrane proteins. In ADP-ribosylation in animal tissue. F. Haag and F. Koch-Nolte, editors. Plenum Press. New York, NY. 365-370.

38. Wei, Y., Yang, X., Liu, Q., Wilkins, J.A., and Chapman, H.A. 1999. A role for caveolin and the urokinase receptor in integrin-mediated adhesion and signaling. J. Cell Biol. 144:1285-1294.

39. Moestrup, S.K., et al. 1993. Epithelial glycoprotein-330 mediates endocytosis of plasminogen activator-plasminogen activator inhibitor type-1 complexes. J. Biol. Chem. 268:16564-16570.

40. Heegaard, C.W., et al. 1995. Very low density lipoprotein receptor binds and mediates endocytosis of urokinase-type plasminogen activator-type-1 plasminogen activator inhibitor complex. J. Biol. Chem. 270:20855-20861.

41. Czekay, R.P., Orlando, R.A., Woodward, L., Lundstrom, M., and Farquhar, M.G. 1997. Endocytic trafficking of megalin/RAP complexes: dissociation of the complexes in late endosomes. Mol. Biol. Cell. 8:517-532.

42. Yamaya, M., Finkbeiner, W.E., Chun, S.Y., and Widdicombe, J.H. 1992. Differentiated structure and function of cultures from human tracheal epithelium. Am. J. Physiol. 262:L713-L724.

43. Zabner, J., Zeiher, B.G., Friedman, E., and Welsh, M.J. 1996. Adenovirusmediated gene transfer to ciliated airway epithelia requires prolonged incubation time. J. Virol. 70:6994-7003.

44. Chiorini, J.A., Kim, F., Yang, L., and Kotin, R.M. 1999. Cloning and characterization of adeno-associated virus type 5. J. Virol. 73:1309-1319.

45. O'Riordan, C.R., et al. 1999. PEGylation of adenovirus with retention of infectivity and protection from neutralizing antibody in vitro and in vivo. Hum. Gene Ther. 10:1349-1358.

46. Nykjaer, A., et al. 1994. Regions involved in binding of urokinase-type-1 inhibitor complex and pro-urokinase to the endocytic alpha 2-macroglobulin receptor/low density lipoprotein receptor-related protein. Evidence that the urokinase receptor protects pro-urokinase against binding to the endocytic receptor. J. Biol. Chem. 269:25668-25676.

47. Estreicher, A., Wohlwend, A., Belin, D., Schleuning, W.D., and Vassalli, J.D. 1989. Characterization of the cellular binding site for the urokinase-type plasminogen activator. J. Biol. Chem. 264:1180-1189.

48. Stoppelli, M.P., et al. 1985. Differentiation-enhanced binding of the aminoterminal fragment of human urokinase plasminogen activator to a specific receptor on U937 monocytes. Proc. Natl. Acad. Sci. USA. 82:4939-4943.

49. Conese, M., and Blasi, F. 1995. Urokinase/urokinase receptor system: internalization/degradation of urokinase-serpin complexes: mechanism and regulation. Biol. Chem. Hoppe Seyler. 376:143-155.

50. Pickles, R.J., Barker, P.M., Ye, H., and Boucher, R.C. 1996. Efficient adenovirus-mediated gene transfer to basal but not columnar cells of cartilaginous airway epithelia. Hum. Gene Ther. 7:921-931.

51. Zabner, J., Freimuth, P., Puga, A., Fabrega, A., and Welsh, M.J. 1997. Lack of high affinity fiber receptor activity explains the resistance of ciliated airway epithelia to adenovirus infection. J. Clin. Invest. 100:1144-1149.

52. Wickham, T.J., et al. 1997. Targeted adenovirus gene transfer to endothelial and smooth muscle cells by using bispecific antibodies. J. Virol. 70:6831-6838.

53. Constantini, V., et al. 1996. Combined overexpression of urokinase, urokinase receptor, and plasminogen activator inhibitor-1 is associated with breast cancer progression. Cancer. 77:1079-1088.

54. Cantero, D., et al. 1997. Enhanced expression of urokinase plasminogen activator and its receptor in pancreatic carcinoma. Br. J. Cancer. 75:388-395.

55. DePetro, G., Tavian, D.C.A., Portolani, N., Giulini, S.M., and Barlati, S. 1998. Expression of urokinase-type plasminogen activator (u-PA), u-PA receptor and tissue-type PA messenger RNAs in human hepatocellular carcinoma. Cancer Res. 58:2234-2239. 